\title{
Luminescent $\mathrm{Eu}^{3+}$-dibenzoylmethanate complex with sulfoxide ligand as sensitizer applied to organic light- emitting diodes
}

\author{
R. Reyes ${ }^{1 *}$, E. Niyama ${ }^{2}$, E.E.S. Teotonio ${ }^{3}$, H.F. Brito ${ }^{2}$, M. Cremona ${ }^{4,5}$ \\ 1. Facultad de Ingeniería Química y Textil, Universidad Nacional de Ingeniería, UNI, Av. Túpac Amaru 210, \\ Lima 31, Perú \\ 2. Instituto de Química, Universidade de São Paulo, USP, C. P. 26077, São Paulo, SP, CEP 05599-970, Brasil \\ 3. Departamento de Química, CCEN, Universidade Federal da Paraíba, UFPB, CP 5093, \\ João Pessoa, PB, CEP 5805-970, Brasil \\ 4. Departamento de Física, Pontifícia Universidade Católica do Rio de Janeiro, PUC-Rio, \\ C. P. 38071, Rio de Janeiro, RJ, CEP 22453-970, Brasil
}

5. DIMAT - Divisão de Metrología de Materiais, Instituto Nacional de Metrología, Normalização e Qualidade Industrial, INMETRO, Duque de Caxias, RJ, Brasil

${ }^{(*)}$ E-mail: fisicaplic@hotmail.com

Received: 17/10/2016 Accepted: 15/05/2017

DOI: $10.7149 /$ OPA.50.2.49012

\begin{abstract}
:
In this work the synthesis, characterization and photoluminescent and electroluminescent behavior of the $\left[\mathrm{Eu}(\mathrm{DBM})_{3}(\mathrm{PTSO})_{2}\right]$ complex have been investigated. The emission spectrum of this $\mathrm{Eu}^{3+}-\beta-$ diketonate complex show characteristics narrow bands arising from the ${ }^{5} \mathrm{D}_{0} \rightarrow \mathrm{F}_{J}(J=0-4)$ transitions, which are split according to the selection rule for $\mathrm{Cs}$, $\mathrm{Cn}$ or $\mathrm{Cnv}$ site symmetries. Triple and doublelayer organic light-emitting diodes (OLEDs) using NPB as hole transporting layer, $\mathrm{Alq}_{3}$ as electron transporting layer and $\left[\mathrm{Eu}(\mathrm{DBM})_{3}(\mathrm{PTSO})_{2}\right]$ complex as emitting and electron transporting layer were grown and characterized. We found the presence of two concurrent mechanisms for the electroluminescent behavior: (1) the electroluminescence (EL) from the exciton-ligand-Eu ${ }^{3+}$ ion energy transfer, responsible for the EL narrow bands; and (2) the molecular electrophosphorescence with an initial energy transfer exciton-ligand and posterior intersystem crossing from the excited singlet $\mathrm{S}_{1}$ to the triplet $\mathrm{T}$ state followed by molecular phosphorescence $\left(\mathrm{T} \rightarrow \mathrm{S}_{0}\right)$. The electroluminescent behavior of $\left[\mathrm{Eu}(\mathrm{DBM})_{3}(\mathrm{PTSO})_{2}\right]$ complex suggest that this complex is promising to applied at Light Conversion Molecular Devices (LCMDs) such as in OLED devices.
\end{abstract}

Key words: Europium; Photoluminescence; Electroluminescence; Electrophosphorescence; OLED

\section{REFERENCES AND LINKS}

[1] B. Geffroy, P.L. Roy, C. Prat, "Organic light-emitting diode (OLED) technology: materials, devices and display technologies," Polym. Int. 55, 572-582 (2006). https://doi.org/10.1002/pi.1974

[2] E.R. Triboni, M.R. Fernandes, J.R. Garcia, M.C. Carreira, R.G.S. Berlinck, P. Berci, L.S. Roman, I.A. Hümmelgen, R. Reyes, M. Cremona, "Naphthalimide-derivative with blue electroluminescence for OLED applications," J. Taibah U. Sci. 9, 579-585 (2015).

https://doi.org/10.1016/i.jtusci.2015.03.013 
[3] R. Reyes, M. Cremona, C.A. Achete, "Light emission in forward and reverse bias operation in OLED with amorphous silicon carbon nitride thin films," J. Phys.: Conf. Ser. 274, 012121 (2011). https://doi.org/10.1088/1742-6596/274/1/012121

[4] C. J. Liang, D. Zhao, Z. R. Hong, D. X. Zhao, X. Y. Liu, W. L. Li, J. B. Peng J. Q. Yu, C. S. Lee S. T. Lee, "Improved performance of electroluminescent devices based on an europium complex," Appl. Phys. Lett. 76, 6769 (2000).

https://doi.org/10.1063/1.125658

[5] H. Xin, M. Shi, X.M. Zhang, F.Y. Li, Z.Q. Bian, K. Ibrahim, F.Q. Liu, C.H. Huang, “Carrier-transport, photoluminescence, and electroluminescence properties comparison of a series of terbium complexes with different structures," Chem. Mater. 15, 3728-3733 (2003).

https://doi.org/10.1021/cm0344414

[6] R. Reyes, E.N. Hering, M. Cremona, C.F.B. Silva, H.F. Brito, C.A. Achete, "Growth and characterization of OLED with samarium complex as emitting and electron transporting layer," Thin Solid Films 420-421, 23-29 (2002). https://doi.org/10.1016/S0040-6090(02)00651-X

[7] Z. Hong, W.L. Li, D. Zhao, C. Liang, X. Liu, J. Peng, D. Zhao, "White light emission from OEL devices based on organic dysprosium-complex," Synth. Met. 111-112, 43-45 (2000). https://doi.org/10.1016/S0379-6779(99)00435-X

[8] Z. Hong, W. Li, D. Zhao, C. Liang, X. Liu, J. Peng, D. Zhao, "Spectrally-narrow blue light-emitting organic electroluminescent devices utilizing thulium complexes," Synth. Met. 104, 165-168 (1999). https://doi.org/10.1016/S0379-6779(99)00060-0

[9] R.J. Curry, W.P. Gillin, "Infra-red and visible electroluminescence from ErQ based OLEDs," Synth. Met. 111-112, 35-38 (2000). https://doi.org/10.1016/S0379-6779(99)00433-6

[10] Z.R. Hong, C.J. Liang, R.G. Li, D. Zhao, D. Fan, W.L. Li, "Infrared electroluminescence of ytterbium complexes in organic light emitting diodes," Thin Solid Films 391, 122-125 (2001). https://doi.org/10.1016/S0040-6090(01)00831-8

[11] H.F. Brito, O.L. Malta, M.C.F.C. Felinto, E.E.S. Teotonio, J.F.S. Menezes, C.F.B. Silva, C.S. Tomiyama, C.A.A. Carvalho, "Luminescence investigation of the Sm(III)- $\beta$-diketonates with sulfoxides, phosphine oxides and amides ligands," J. Alloys and Comp. 344, 293-297 (2002). https://doi.org/10.1016/S0925-8388(02)00372-9

[12] J.M. Lehn, "Perspectives in supramolecular chemistry-from molecular recognition towards molecular information processing and self-organization," Angew. Chem. Int. Ed. Engl. 29, 1304-1319 (1990) https://doi.org/10.1002/anie.199013041

[13] E. Niyama, H.F. Brito, M. Cremona, E.E.S. Teotonio, R. Reyes, G.E.S. Brito, M.C.F.C. Felinto, "Synthesis and spectroscopic behavior of highly luminescent $\mathrm{Eu}^{3+}$-dibenzoylmethanate (DBM) complexes with sulfoxide ligands," Spectrochim. Acta Part A 61, 2643-2649 (2005). https://doi.org/10.1016/j.saa.2004.10.006

[14] H.G. Liu, S. Park, K.W. Jang, X.S. Feng, C.D. Kim, H.J. Seo, Y.I. Lee, "Influence of ligands on the photoluminescent properties of $\mathrm{Eu}^{3+}$ in europium $\beta$-diketonate/PMMA-doped systems," J. Lumin. 106, 47-55 (2004). https://doi.org/10.1016/S0022-2313(03)00133-9

[15] R.G. Charles, A. Perroto, "Rare earth dibenzoylmethides preparation, dehydration and thermal stability," J. Inorg. Nucl. Chem. 26, 373-376 (1964). https://doi.org/10.1016/0022-1902(64)80081-6

[16] W. Quirino, R. Reyes, C. Legnani, P.C. Nóbrega, P.A. Santa-Cruz, M. Cremona, "Eu- $\beta$-diketonate complex OLED as UV portable dosimeter," Synth. Met. 161, 964-968 (2011). https://doi.org/10.1016/j.synthmet.2011.03.001

[17] A. Kirby, F.S. Richardson, "Detailed analysis of the optical absorption and emission spectra of europium( ${ }^{3+}$ ) in the trigonal (C3) Eu(DBM) $)_{3} \cdot \mathrm{H}_{2} \mathrm{O}$ system," J. Phys. Chem. 87, 2544-2556 (1983). https://doi.org/10.1021/j100237a018

[18] R. Reyes, M. Cremona, E.E.S. Teotonio, H.F. Brito, O.L. Malta, "Molecular electrophosphorescence in (Sm, Gd)-b-diketonate complex blend for OLED applications," Journal of Luminescence 134, 369-373 (2013). https://doi.org/10.1016/i.jlumin.2012.08.019

[19] F. Garten, A.R. Schlatmann, R.E. Gill, J. Vrijmoeth, T.M. Klapwijk, G. Hadziioannou, "Light emission in reverse bias operationfrom poly(3-octylthiophene)-based light emitting diodes," Appl.Phys. Lett. 66, 
2540-2542 (1995).

https://doi.org/10.1063/1.113160

\section{Introduction}

An organic light-emitting diode (OLED) has an electroluminescent layer of organic compound and other layers that are made up of small organic molecules or macro polymers that conduct electricity, and these layers are placed between two electrodes, where at least one layer is transparent. OLED offers many advantages and solutions in display technology and is reported to have lower weight and smaller dimension, variety of color, and lower voltage consumption. Organic dyes, metal complexes, and polymers have been extensively studied as emitting materials $[1,2,3]$.

Trivalent rare earth ions $\left(\mathrm{RE}^{3+}\right)$ have been used as emitting centers, in particular the complexes containing $\mathrm{Eu}^{3+}[4]$ and $\mathrm{Tb}^{3+}[5]$ ions that emit red and green light, respectively. The orange light was attained using the $\mathrm{Sm}^{3+}$ ion [6], white con $\mathrm{Dy}^{3+}$ [7], blue with $\mathrm{Tm}^{3+}$ [8] and infrared emission was achieved with $\mathrm{Er}^{3+}$ [9] and $\mathrm{Yb}^{3+}[10]$, raising the interest on OLEDs devices for telecommunication applications. In contrast, the $\mathrm{Gd}^{3+}$ ion has an energy gap between the ${ }^{8} \mathrm{~S}_{7 / 2}$ ground state and first excited state ${ }^{6} \mathrm{P}_{7 / 2}$ at around $32000 \mathrm{~cm}^{-}$ 1 , and its complexes are used to study the energy of the triplet states $\mathrm{T}$ of the organic ligand [11].

The absorption and emission spectra of the $\mathrm{RE}^{3+}$ ions show weak intensity because the intraconfigurational $4 \mathrm{f}-4 \mathrm{f}$ transitions in rare earth ions are parity forbidden. But coordinating the $\mathrm{RE}^{3+}$ to organic ligands, which act as sensitizers and works as "antennas" [12], the population of the excited states of the RE ${ }^{3+}$ ions may be increased. With the intramolecular energy transfer process occurring in $\mathrm{RE}^{3+}$ - complexes, the organic ligands absorb and transfer energy efficiently to the metal ion and consequently increasing their luminescence intensity. Due to the effective shield of the $4 \mathrm{f}^{\mathrm{N}}$ orbitals from influence of the chemical environment by the $5 \mathrm{~s} 5 \mathrm{p}$ orbitals, the $\mathrm{RE}^{3+}$ ions shown narrow bands, then the $\mathrm{RE}^{3+}$-complexes exhibit almost pure color (quasi-monochromatic behavior), which is one of the advantages of $\mathrm{RE}^{3+}$ ions.

Due to their higher luminescence intensity, the $\mathrm{RE}^{3+}$-complexes with $\beta$-diketonate ligands as sensitizers have attracted research interest. Also by their high absorption coefficient and the very efficient ligand-tometal ions energy transfer, the $\mathrm{Eu}^{3+}$-dibenzoylmethanate (Eu$\left.{ }^{3+}-\mathrm{DBM}\right)$ ternary complexes have exhibited desirable photo and electroluminescent properties [13]. Considering that the lowest excited triplet state $T$ of DBM ligand is found at around $21,600 \mathrm{~cm}^{-1}$ and since the position of the triplet states of the ligands play an important role in the intramolecular energy transfer process of the $\mathrm{RE}^{3+}$-complexes, then the DBM ligand acts as a good "antenna" for the $\mathrm{Eu}^{3+}$ ion [14]. Generally, in $\mathrm{Eu}^{3+}$-coordination compounds the energy transfer occurs from triplet state $\mathrm{T}$ of the organic ligand to the excited ${ }^{5} \mathrm{D}_{J}$ level $(J=0,1,2)$. Because the energy transfer probability from $T$ state to ${ }^{5} \mathrm{D}_{0}$ level is very small, except when the ligand triplet state is located between the ${ }^{5} \mathrm{D}_{1}$ and ${ }^{5} \mathrm{D}_{0}$ states, then by their $\mathrm{T}$ state position, the Eu-DBM complexes present the resonance conditions favoring the ligand-to-metal energy transfer $T \rightarrow{ }^{5} D_{1}$.

In this work, we present the synthesis and characterization of the luminescent europium complex $\left[\mathrm{Eu}(\mathrm{DBM})_{3}(\mathrm{PTSO})_{2}\right]$, containing dibenzoylmethane (DBM) and $p$-tolyl sulfoxide (PTSO) as ligand. Additionally the $\left[\mathrm{Gd}(\mathrm{DBM})_{3}(\mathrm{PTSO})_{2}\right]$ complex also was synthesized to investigation purpose. In order to demonstrate the possibility of application of the $\left[\mathrm{Eu}(\mathrm{DBM})_{3}(\mathrm{PTSO})_{2}\right]$ complex in the fabrication of Light Conversion Molecular Devices (LCMD) such as OLED devices, typical OLED devices using N,N'-bis(1naphtyl)-N,N'-diphenyl-1,1'-biphenyl-4,4'-diamine (NPB) as hole-transporting layer, [Eu(DBM) $3(\mathrm{PTSO})_{2}$ ] used as emitting layer and tris(8-hydroxyquinolinato)aluminum ( $\mathrm{Alq}_{3}$ ) as electron transporting layer were fabricated and characterized. Furthermore, in order to investigate the possibility to use the europium complex working simultaneously both as emitting and electron transporting layer another device without $\mathrm{Alq}_{3}$ was grown. Consequently, a total of two different device configurations were prepared and characterized.

\section{Experimental}

According to a previously described procedure [13], $\mathrm{RECl}_{3} \bullet 6 \mathrm{H}_{2} \mathrm{O}\left(\mathrm{RE}^{3+}=\mathrm{Eu}\right.$ and Gd) were prepared from $\mathrm{RE}_{2} \mathrm{O}_{3}$ (from Aldrich) and hydrochloride acid (from Merck). The dibenzoylmethane (from Merck) and sulfoxide ligand p-tolyl sulfoxide (PTSO) was purchased from Aldrich and used as received. The $\left[\mathrm{RE}(\mathrm{DBM})_{3} \bullet \mathrm{H}_{2} \mathrm{O}\right]$ complex utilized as precursors were synthesized according to an method described 
elsewhere [15]. In the preparation of the $\left[\operatorname{RE}(\mathrm{DBM})_{3}(\mathrm{PTSO})_{2}\right]$ complexes with sulfoxide ligands the precursor hydrated complex and sulfoxide ligand were separately dissolved in acetone and mixed in 1:2 (hydrated complex: sulfoxide ligand) molar ratio. After evaporation of the solvent a viscous product was produced, which was dried under vacuum in presence of phosphorus pentoxide as secant agent in desiccator.

The carbon and hydrogen contents were determined from elemental analyses, using a Perkin-Elmer model 240 microanalyzer, while the $\mathrm{RE}^{3+}$ contents (Eu and Gd) were performed by complexometric titration with EDTA. The infrared absorption spectra of the free ligands (DBM and PTSO) and complexes in KBr pellets were recorded in the spectral range of $400-4000 \mathrm{~cm}^{-1}$ on a Bomen model MB-102 spectrophotometer. OLED's devices with two different configurations were obtained, the first one with $\left[\mathrm{Eu}(\mathrm{DBM})_{3}(\mathrm{PTSO})_{2}\right]$ as the emitting layer. In the second configuration the $\left[\mathrm{Eu}(\mathrm{DBM})_{3}(\mathrm{PTSO})_{2}\right]$ worked as emitting and electrontransporting layer and so the produced OLEDs present the following configurations:

Device 1: ITO/NPB(50 nm)/[Eu(DBM $)_{3}\left(\mathrm{PTSO}_{2}\right](50 \mathrm{~nm}) / \mathrm{Alq}_{3}(50 \mathrm{~nm}) / \operatorname{Al}(120 \mathrm{~nm})$

Device 2: ITO/NPB(50 nm)/ [Eu(DBM $\left.)_{3}(\mathrm{PTSO})_{2}\right](50 \mathrm{~nm}) / \operatorname{Al}(120 \mathrm{~nm})$

The NPB and the $\mathrm{Alq}_{3}$ were used as obtained and the compounds were sequentially deposited by thermal evaporation onto indium-tin oxide (ITO) glass substrates at room temperature, with a sheet resistance of $8.1 \Omega /$. The substrates were initially cleaned by ultrasonification using a detergent solution, followed by toluene degreasing and then cleaned again by ultrasonification with pure isopropyl alcohol. After drying on the spinner at $5000 \mathrm{rpm}$ for 1 minute, the substrates were loaded into the vacuum chamber. The base pressure was $5 \times 10^{-6}$ Torr and during the evaporation, the pressure was $\sim 8 \times 10^{-6}$ Torr. The rates of deposition of the compounds were in the range of 0.1 to $0.3 \mathrm{~nm} / \mathrm{s}$. Tungsten crucibles were used to evaporate the organic compounds. Finally, a $120 \mathrm{~nm}$ thick aluminum cathode was evaporated from a tungsten wire basket at a rate of approximately $2.0 \mathrm{~nm} / \mathrm{s}$ in the same vacuum chamber. A shadow mask with $0.5 \times 0.5 \mathrm{~cm}^{2}$ opening was used to shape the cathode. The layer thickness was controlled in situ through a quartz crystal monitor $[2,3,16]$.

The absorption spectrum in the optical range of the $\mathrm{Eu}^{3+}$-complex films was recorded on a Perkin-Elmer Lambda 19 spectrophotometer and the photoluminescent and electroluminescence spectra were obtained in a Photon Technology International (PTI) fluorescence spectrophotometer. The brightness was measured by using a calibrated radiometer/photometer by United Detector Technology (UDT-350).

\section{Results and discussion}

With the carbon and hydrogen contents estimated by microanalytical procedures and the Eu, Gd contents determined by complexometric titration with EDTA, the C, H, Eu and Gd percentage values calculated / found for the complexes with their respective ligands were: a) Europium complex [Eu(DBM) $\left.)_{3}(\mathrm{PTSO})_{2}\right]$; $(\mathrm{C}$ : 68.37 / 68.26; H: 4.79 / 4.94; Eu ${ }^{3+}: 11.57$ / 11.85), b) Gadolinium complexes [Gd(DBM) $3($ PTSO) 2 ; (C: 68.09 / 68.45; H: 4.77 / 4.82; $\mathrm{Gd}^{3+}: 12.21$ / 12.07).

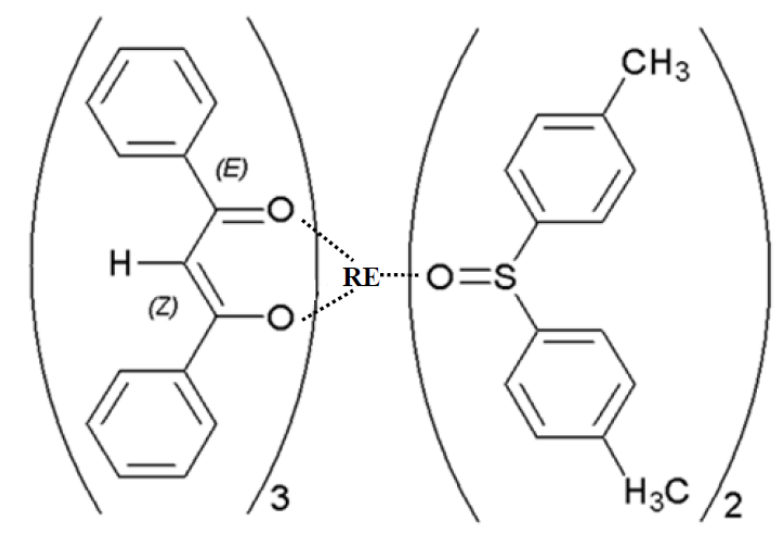

Fig.1. The chemical structure of $\left[\operatorname{RE}(\mathrm{DBM})_{3}(\mathrm{PTSO})_{2}\right]$ complex. RE: Eu or Gd. 
As it can be seen above the elemental analysis data are in good concordance with the general formula $\left[\mathrm{RE}(\mathrm{DBM})_{3}(\mathrm{PTSO})_{2}\right]$. It is observed that two sulfoxide ligands are coordinated to trivalent rare earth ions (Fig. 1), indicating the higher coordinating ability of the sulfoxide ligands that overcome the steric interactions as compared with the water molecule [13].

The optical absorption, excitation and the photoluminescence (PL) spectra of the [Eu(DBM) $\left.)_{3}(\mathrm{PTSO})_{2}\right]$ thin film deposited onto a quartz substrate and recorded at room temperature are shown in Fig. 2. The absorption spectrum (Fig. 2-a) shows clearly the ligand excitation band around $350 \mathrm{~nm}$, corresponding to $\mathrm{S}_{0} \rightarrow \mathrm{S}_{1}$ transition. The excitation spectrum in the spectral range from 200 to $590 \mathrm{~nm}$, under emission on hypersensitive ${ }^{5} \mathrm{D}_{0} \rightarrow{ }^{7} \mathrm{~F}_{2}$ transition at $612 \mathrm{~nm}$ (Fig. 2-b), shown that the efficient excitation is in the ultraviolet region and the maximum is located also at $350 \mathrm{~nm}$, corresponding to $\mathrm{S}_{0} \rightarrow \mathrm{S}_{1}$ transition. This excitation spectrum display a broad high intensity band in the range $250-430 \mathrm{~nm}$, which is attributed to the DBM centered transition, evidencing that the excitation of $\mathrm{Eu}^{3+}$ ion is caused by an indirect process via an efficient intramolecular energy transfer from DBM to this metal ion.

In the PL spectrum (Fig. 2-c), recorded in the range of 450-720 nm under excitation at around $350 \mathrm{~nm}$, and considering their amplification in the inset, it is observed the presence of narrow bands around 536, 579, $593,612,652$ and $700 \mathrm{~nm}$ originated from the ${ }^{5} \mathrm{D}_{1} \rightarrow{ }^{7} \mathrm{~F}_{1},{ }^{5} \mathrm{D}_{0} \rightarrow{ }^{7} \mathrm{~F}_{0},{ }^{5} \mathrm{D}_{0} \rightarrow{ }^{7} \mathrm{~F}_{1},{ }^{5} \mathrm{D}_{0} \rightarrow{ }^{7} \mathrm{~F}_{2},{ }^{5} \mathrm{D}_{0} \rightarrow{ }^{7} \mathrm{~F}_{3}$ and ${ }^{5} \mathrm{D}_{0}$ $\rightarrow{ }^{7} \mathrm{~F}_{4}$ transitions of the trivalent $\mathrm{Eu}^{3+}$ ion, respectively. The emission spectrum is dominated by the highest luminescence intensity from the hypersensitive ${ }^{5} \mathrm{D}_{0} \rightarrow{ }^{7} \mathrm{~F}_{2}$ transition. The presence of only one peak corresponding to ${ }^{5} \mathrm{D}_{0} \rightarrow{ }^{7} \mathrm{~F}_{0}$ transition around $579 \mathrm{~nm}$ (Fig. 2-c) suggests the existence of one local site of symmetry for the Eu-complex. Additionally, the presence of the ${ }^{5} \mathrm{D}_{0} \rightarrow{ }^{7} \mathrm{~F}_{0}$ transition suggests that the europium ion reside at $\mathrm{Cs}, \mathrm{Cn}$ or $\mathrm{Cnv}$ site symmetries. According to the emission spectral data of the $\left[\mathrm{Eu}(\mathrm{DBM})_{3}(\mathrm{PTSO})_{2}\right]$ complex, this shown unusually high intensity ${ }^{5} \mathrm{D}_{0} \rightarrow{ }^{7} \mathrm{~F}_{3}$ transition, which was found to be somewhat stronger than it was observed for most other luminescent $\mathrm{Eu}^{3+}$ coordination compounds [17]. This behavior indicates that there is a significant $J-J$ mixing for that for the ${ }^{5} \mathrm{D}_{0} \rightarrow{ }^{7} \mathrm{~F}_{3}$ transition to acquire dipole strength.

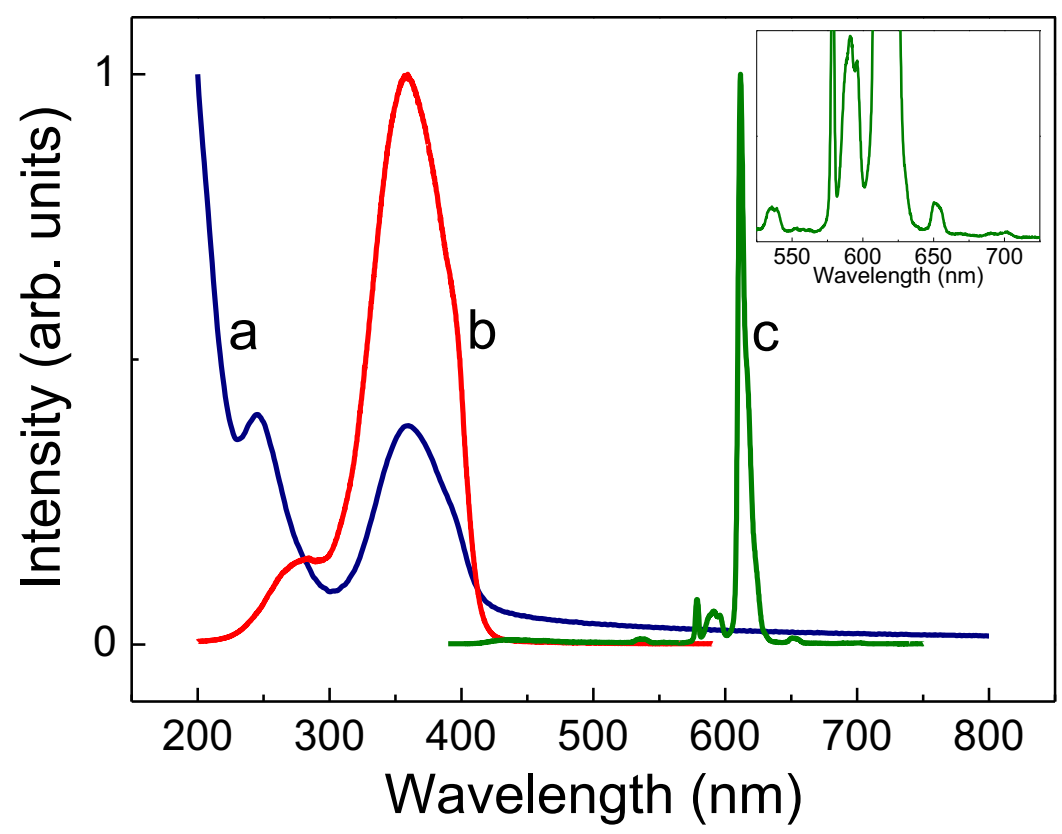

Fig.2. Spectral data of the film $\left[\mathrm{Eu}(\mathrm{DBM})_{3}(\mathrm{PTSO})_{2}\right]$ complex, measured at room temperature: a) absorption spectrum, b) excitation spectrum under emission at $612 \mathrm{~nm}$ and c) photoluminescent spectrum under excitation at $348 \mathrm{~nm}$ band. Inset is the amplification of PL spectrum.

The emission spectrum of the $\left[\mathrm{Gd}(\mathrm{DBM})_{3}(\mathrm{PTSO})_{2}\right]$ complex at $77 \mathrm{~K}$, with excitation monitored at ligand $\mathrm{S}_{0} \rightarrow \mathrm{S}_{1}$ transition around $350 \mathrm{~nm}$ is showed in Fig. 3-a. For comparison, the emission spectrum of the $\left[\mathrm{Eu}(\mathrm{DBM})_{3}(\mathrm{PTSO})_{2}\right]$ complex recorded also at $77 \mathrm{~K}$, with excitation around $350 \mathrm{~nm}$ is showed in Fig. 3-b. The emission spectrum of the $\mathrm{Gd}^{3+}$ complex is appropriate to obtain information on the energy levels of the organic ligands, considering that the first excited ${ }^{6} \mathrm{P}_{7 / 2}$ level of the trivalent gadolinium ion is around 32,000 $\mathrm{cm}^{-1}$ above the ${ }^{8} \mathrm{~S}_{7 / 2}$ ground state. Generally, the triplet states of organic ligands are located bellow the ${ }^{6} \mathrm{P}_{7 / 2}$ 
level from $\mathrm{Gd}^{3+}$ ion, hindering the intramolecular energy transfer from organic ligands to gadolinium ion. When examining the luminescence spectra of $\left[\mathrm{Eu}(\mathrm{DBM})_{3}(\mathrm{PTSO})_{2}\right]$ complex in Fig. 3-b an broad band is not displayed in the interval of 480-700 nm arising from phosphorescence of the organic ligands such as in the $\left[\mathrm{Gd}(\mathrm{DBM})_{3}(\mathrm{PTSO})_{2}\right]$. These spectral data indicate that the energy transfer from lowest triplet state of the DBM ligands to europium ion is very efficient in this case of excitation with photons. Since the fluorescence bands (400-470 $\mathrm{nm}$ ) from singlet state of the DBM ligand are not presented in the emission spectrum of the $\mathrm{Eu}^{3+}$-complex, the intramolecular energy transfer can also be occurring from the $\mathrm{S}_{1}$ state to the excited ${ }^{5} \mathrm{D}_{4}$ or ${ }^{5} \mathrm{~L}_{6}$ levels of the $\mathrm{Eu}^{3+}$ ion.

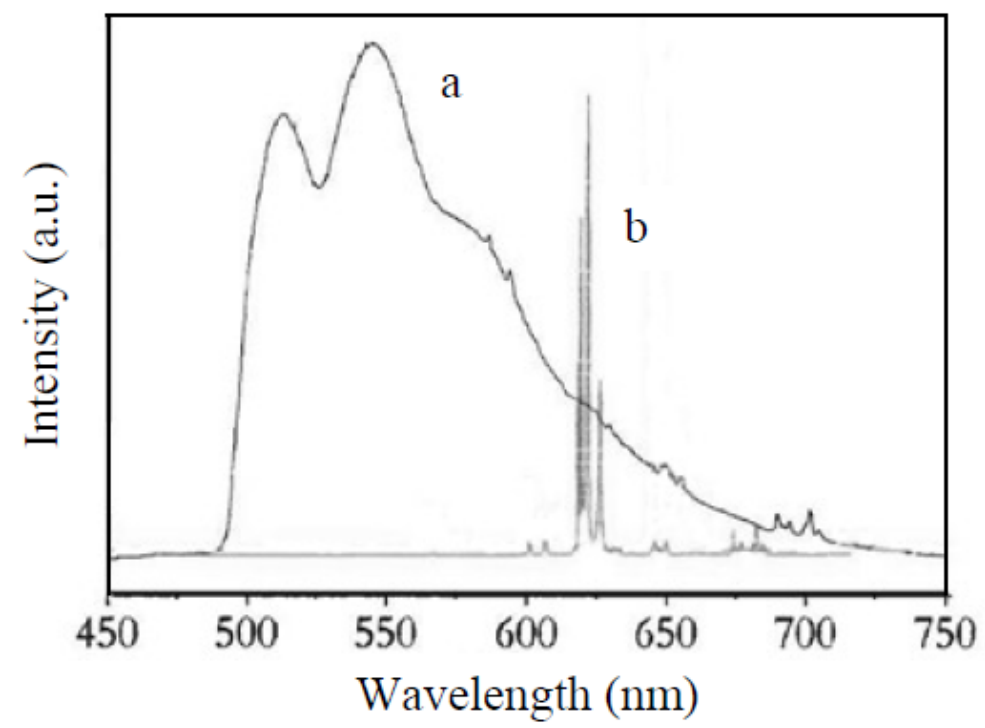

Fig.3. Photoluminescent spectra under excitation at $350 \mathrm{~nm}$, measured at $77 \mathrm{~K}$ of: a) $\left.\left[\mathrm{Gd}(\mathrm{DBM})_{3}(\mathrm{PTSO})_{2}\right]_{\mathrm{and}} \mathrm{b}\right)\left[\mathrm{Eu}(\mathrm{DBM})_{3}(\mathrm{PTSO})_{2}\right]_{\text {. }}$

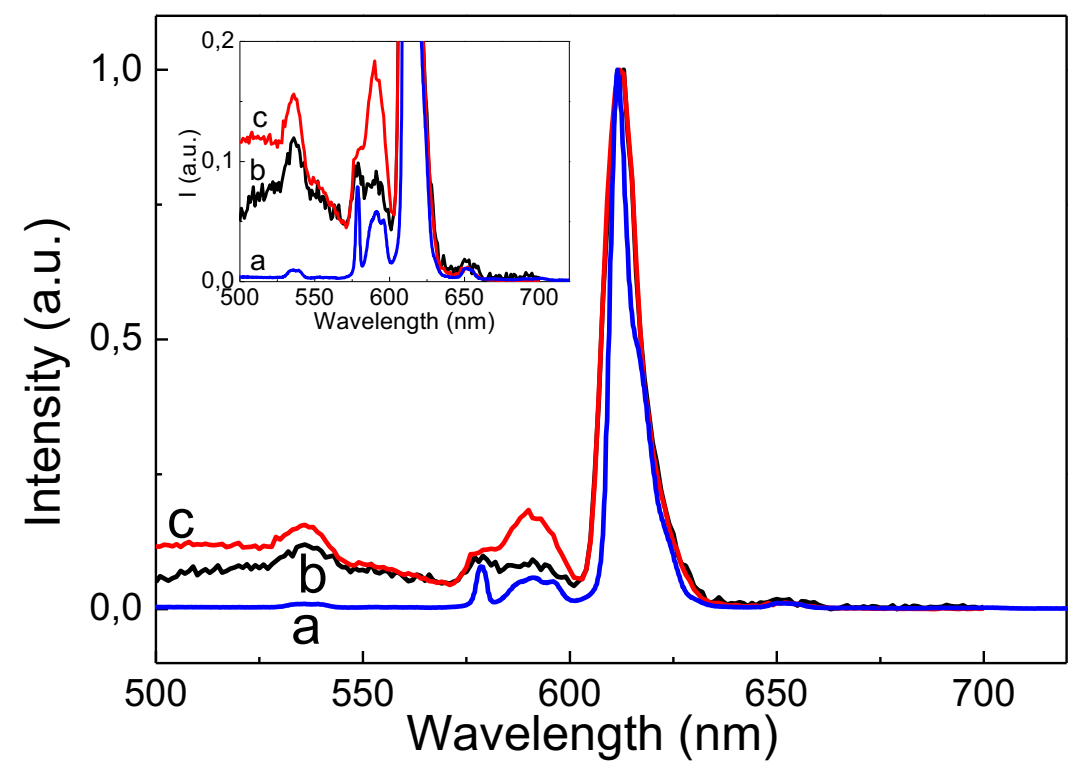

Fig.4. Spectral data obtained at room temperature: a) photoluminescence spectrum of thin film [Eu(DBM) $\left.)_{3}(\mathrm{PTSO})_{2}\right]_{\text {, b }}$ EL spectra of device 1 for bias voltage of $14 \mathrm{~V}$ and c) EL spectrum of device 2 for bias voltage of $14 \mathrm{~V}$. Inset showing the electrophosphorescence detection amplified.

Fig. 4 shown the photoluminescence spectrum of the $\left[\mathrm{Eu}(\mathrm{DBM})_{3}(\mathrm{PTSO})_{2}\right]$ complex thin film deposited onto a glass substrate (Fig. 4-a), electroluminescence spectrum of the device 1 with the europium complex as emitting layer (Fig. 4-b) and electroluminescence spectrum of the device 2 with the europium complex as emitting and electron transport layer (Fig. 4-c), at room temperature. The applied bias voltage for devices 1 and 2 was $14 \mathrm{~V}$. The EL spectra of devices 1 and 2 present the characteristic emission bands arising from 
the $\mathrm{Eu}^{3+}$ ion as that at the PL of complex in thin film form. We can identify in Figs. 4-b and 4-c the bands around 536, 579, 593, 612 and 652 as originated from the ${ }^{5} \mathrm{D}_{1} \rightarrow{ }^{7} \mathrm{~F}_{1},{ }^{5} \mathrm{D}_{0} \rightarrow{ }^{7} \mathrm{~F}_{0},{ }^{5} \mathrm{D}_{0} \rightarrow{ }^{7} \mathrm{~F}_{1},{ }^{5} \mathrm{D}_{0} \rightarrow{ }^{7} \mathrm{~F}_{2}$ and ${ }^{5} \mathrm{D}_{0}$ $\rightarrow{ }^{7} \mathrm{~F}_{3}$ transitions of the trivalent $\mathrm{Eu}^{3+}$ ion, respectively. The band corresponding around $700 \mathrm{~nm}$ originated from ${ }^{5} \mathrm{D}_{0} \rightarrow{ }^{7} \mathrm{~F}_{4}$ transition is not distinguished in the EL spectra. The EL emission of devices 1 and 2 is dominated, as in the PL spectrum, by the highest luminescence intensity from the hypersensitive ${ }^{5} \mathrm{D}_{0} \rightarrow{ }^{7} \mathrm{~F}_{2}$ transition around $612 \mathrm{~nm}$.

In Figs. 4-b-c, corresponding to electroluminescence of devices 1 and 2, one can notice between 500 and $600 \mathrm{~nm}$ the presence of a band above the spectrum of photoluminescence (Fig. 4-a) of the europium complex. In the inset of the Fig. 4 one can notice more clearly the presence of this band between 500 and $600 \mathrm{~nm}$, approximately, on which are mounted 4 bands corresponding to the transitions ${ }^{5} \mathrm{D}_{1} \rightarrow{ }^{7} \mathrm{~F}_{1}(536$ $\mathrm{nm}),{ }^{5} \mathrm{D}_{0} \rightarrow{ }^{7} \mathrm{~F}_{0}(579 \mathrm{~nm}),{ }^{5} \mathrm{D}_{0} \rightarrow{ }^{7} \mathrm{~F}_{1}(593 \mathrm{~nm})$ and ${ }^{5} \mathrm{D}_{0} \rightarrow{ }^{7} \mathrm{~F}_{2}(612 \mathrm{~nm})$ of the ion $\mathrm{Eu}^{3+}$.

The presence of the bands between 500 and $600 \mathrm{~nm}$ in the EL spectra of devices 1 and 2 we can assign to electrophosphorescence from $\mathrm{T} \rightarrow \mathrm{S}_{0}$ transition centered in the DBM ligand, which is in concordance with the band form in the PL spectrum of the $\left[\mathrm{Gd}(\mathrm{DBM})_{3}(\mathrm{PTSO})_{2}\right]$ complex showed in the Fig. 3, where the emission spectra of the Gd-complex exhibit intense broad band in the spectral range from 480 to $720 \mathrm{~nm}$ with a maximum at about $544 \mathrm{~nm}$ assigned also to the phosphorescence from $\mathrm{T} \rightarrow \mathrm{S}_{0}$ transition centered in the DBM ligand.

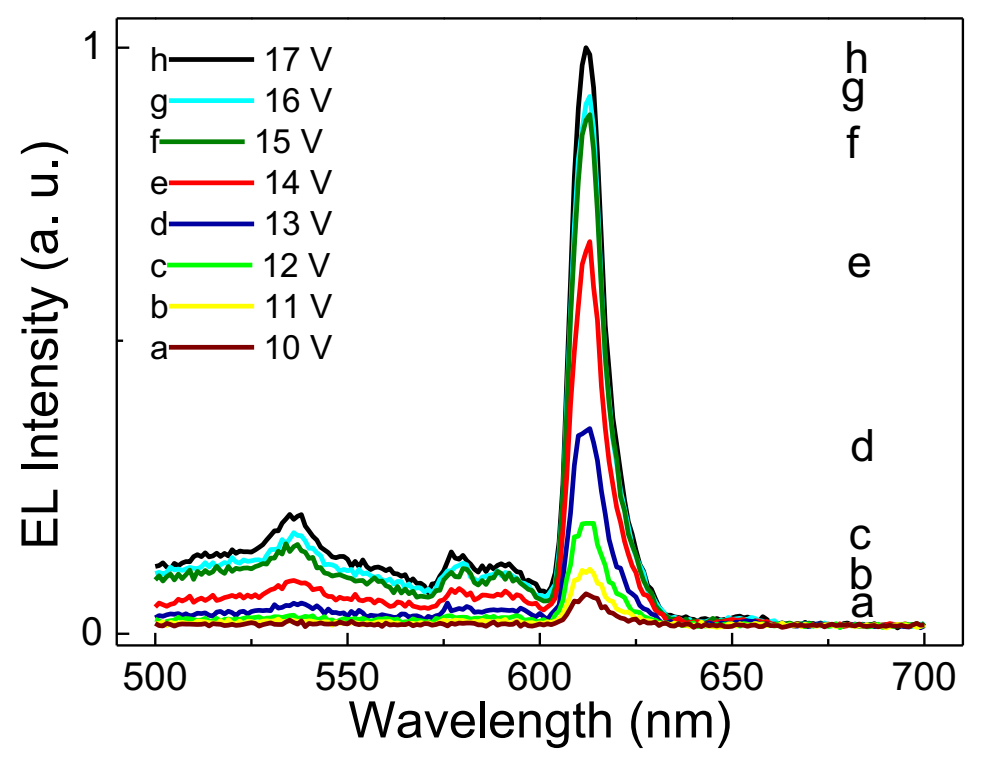

Fig.5. Electroluminescent spectra of device 1 recorded at bias-voltages from 10 to $17 \mathrm{~V}$.

Fig. 5 presents the EL spectra of the device 1 turn on voltage in range of 10 to $17 \mathrm{~V}$ of bias voltage. In this figure is possible to observe that when the bias voltage is increased up to $17 \mathrm{~V}$, the EL spectrum exhibits clearly the electrophosphorescence from the DBM ligand, which is also present in the EL spectrum of the device 2, such as was observed at Fig. 4-c. The luminescence intensities of the sharp lines attributed to the ${ }^{5} \mathrm{D}_{1} \rightarrow{ }^{7} \mathrm{~F}_{1}(536 \mathrm{~nm}),{ }^{5} \mathrm{D}_{0} \rightarrow{ }^{7} \mathrm{~F}_{0}(579 \mathrm{~nm}),{ }^{5} \mathrm{D}_{0} \rightarrow{ }^{7} \mathrm{~F}_{1}(593 \mathrm{~nm})$ and ${ }^{5} \mathrm{D}_{0} \rightarrow{ }^{7} \mathrm{~F}_{2}(612 \mathrm{~nm})$ of the ion Eu $\mathrm{Eu}^{3+}$ transitions increase as the voltage is increased from 10 up to $17 \mathrm{~V}$. Thus, in the devices 1 and 2 are expected two concurrent mechanisms: the electroluminescence one via energy transfer from exciton to ligand and after $\mathrm{Eu}^{3+}$ ion, where the narrow bands observed in the EL spectra arise from the $\mathrm{Eu}^{3+}$ ion; and other the mechanism of molecular electrophosphorescence with an initial energy transfer from exciton to ligand and posterior intersystem crossing from the excited singlet $S_{1}$ to the triplet $T$ state followed by molecular electrophosphorescence $\left(\mathrm{T} \rightarrow \mathrm{S}_{0}\right)$. These results suggest that, in this europium complex $\left[\mathrm{Eu}(\mathrm{DBM})_{3}(\mathrm{PTSO})_{2}\right]$, probably the energy transfer exciton-ligand- $\mathrm{RE}^{3+}$ ion is altered by the presence of electrons of the electric current, showing a phosphorescence in the electroluminescent spectra. This is in contrast with the case of the same $\mathrm{Eu}^{3+}$ complex excited by photons in the photoluminescence in which no phosphorescence from the DBM ligand is observed (Fig. 4-a). This same fact of the apparition of an electrophosphorescence band for the electronic excitation of the emitting material in the organic diodes but not with photonic excitation of the same emitting material was clearly observed also in organic diodes with a samarium complex [18]. 
Fig. 6 shows the current density $J$ and the EL intensity as a function of the voltage applied to the device 1 . It is interesting to observe that up to $18 \mathrm{~V}$, the $J-V$-curve and the EL-intensity-curve initially have the same shape, suggesting a balanced injection and an approximately constant radiative recombination rate of electrons and holes at the emitting layer [Eu(DBM) $\left.)_{3}(\mathrm{PTSO})_{2}\right]$ [19].

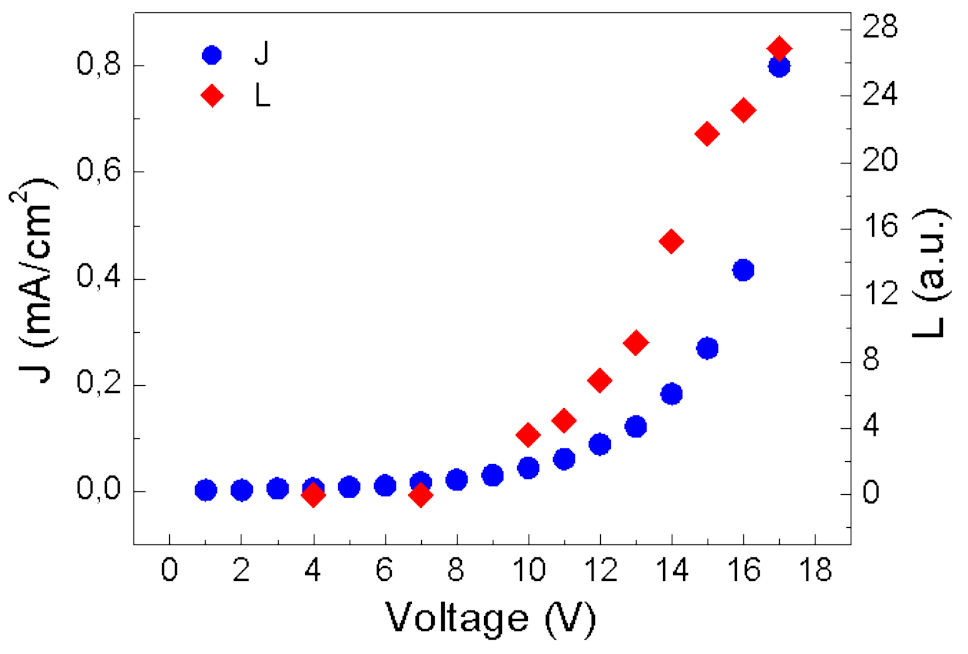

Fig.6. Current-voltage and luminance-voltage characteristics of device 1.

The chromaticity according to the Commision Internationale D`Eclairage (CIE) for the PL of complex $\left[\mathrm{Eu}(\mathrm{DBM})_{3}(\mathrm{PTSO})_{2}\right]$ in thin film form and EL of devices 1 and 2 with $14 \mathrm{~V}$ of bias-voltage is showed in Fig. 7. In the case of PL thin film of complex $\left[\mathrm{Eu}(\mathrm{DBM})_{3}(\mathrm{PTSO})_{2}\right]$, with $\mathrm{x}=0.66$ and $\mathrm{y}=0.31$ chromaticity coordinates, it is observed that the emitted color is quasi monochromatic red and in this case is not present the electrophosphorescence emission of DBM ligand as is seen in Fig. 4. On the other hand, the chromaticity of the devices 1 and 2 are influenced by the electrophosphorescence emission band of DBM ligand that can to be observed in Fig. 4. Thus, in device 1, with chromaticity coordinates $x=0.59$ and $y=0.38$, the emitted color exhibits a shift to orange due to contribution of the molecular electrophosphorescence from the DBM ligand. A similar behavior is observed for the device 2, where the emitted color $(\mathrm{x}=0.55, \mathrm{y}=0.32)$ is shift to a red-violet color due to the higher contribution of molecular electrophosphorescence from the DBM ligand when compared with EL spectra of device 1, as is appreciated in Fig. 4 and their inset.

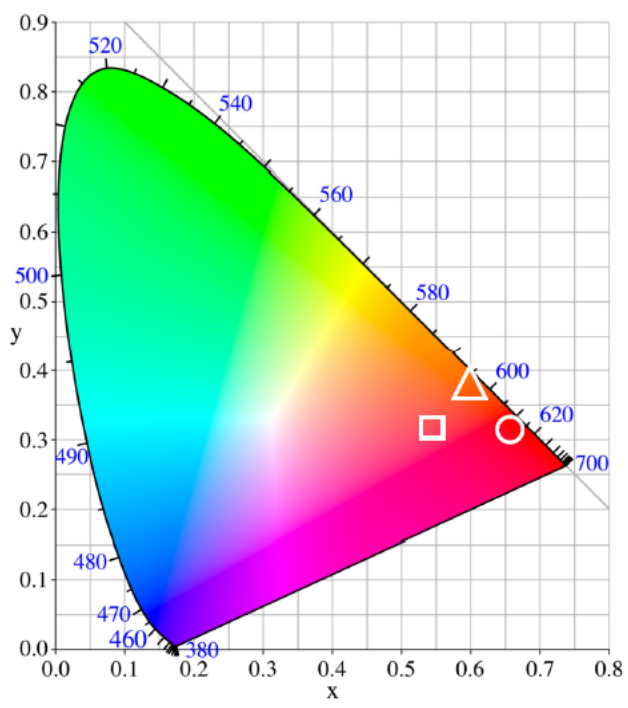

Fig.7. The CIE x,y chromaticity of: PL of $\left[\mathrm{Eu}(\mathrm{DBM})_{3}(\mathrm{PTSO})_{2}\right]$ film $(\mathrm{O})$, EL of device $1(\Delta)$, and EL of device $2(\mathrm{)})$. 


\section{Conclusions}

In this work the synthesis, characterization and photoluminescent and electroluminescent behavior of the $\left[\mathrm{Eu}(\mathrm{DBM})_{3}(\mathrm{PTSO})_{2}\right]$ complex have been investigated. The emission spectra of the $\mathrm{Eu}^{3+}-\beta$-diketonate complex show characteristics narrow bands arising from the ${ }^{5} \mathrm{D}_{0} \rightarrow{ }^{7} \mathrm{~F}_{J}(\mathrm{~J}=0-4)$ transitions, which are split according to the selection rule for Cs, Cn or Cnv site symmetries.

Triple and double-layer electroluminescent organic diodes using NPB as hole transporting layer, $\mathrm{Alq}_{3}$ as electron transporting layer and $\left[\mathrm{Eu}(\mathrm{DBM})_{3}(\mathrm{PTSO})_{2}\right]$ complex as emitting and electron transporting layer too were grown and characterized. The EL spectra of the devices exhibit emission characteristics of the sharp lines from the $\mathrm{Eu}^{3+}$ ion together with a broad band arising from the molecular electrophosphorescence of the DBM ligand that is not observed in the photoluminescent spectra of the film of the same complex. The electroluminescent behavior of $\left[\mathrm{Eu}(\mathrm{DBM})_{3}(\mathrm{PTSO})_{2}\right]$ complex suggest that this complex is promising to applied at Light Conversion Molecular Devices (LCMDs) such as in OLEDs. Further investigations are in progress to improve these studies and to better understand the differences between photonic and electrical excitation in these rare earth chelates.

\section{Acknowledgements}

The authors thank to CNPq, FAPERJ, FAPESP, RENAMI and IGI-UNI for the financial support and Prof. Sonia R.W. Louro (PUC-Rio) for the use of the spectrofluorimeter. Portions of this work were presented at the RIAO/OPTILAS 2016. 